\title{
CHANGES IN FINANCIAL AND ACCOUNTING ENVIRONMENT IN ALBANIA AND THE IMPACT ON PRACTITIONERS.
}

\author{
Rezarta Shkurti (Perri) $)^{1}$ \\ Brikena Leka $(\text { Gjoni })^{2}$ \\ Rovena Bahiti ${ }^{3}$ \\ Elfrida Manoku (Gishto) ${ }^{4}$
}

\begin{abstract}
This paper presents a theoretical discussion about the organization of the professions of accounting and auditing in Albania and the most recent changes that have encompassed the Albanian financial and accounting landscape after the implementation of new accounting standards, the increased requirements for electronic financial and tax reporting and the ongoing improvement and adaptation of the higher education curricula. All these factors present major challenges for the field practitioners in accounting and auditing. We try to identify which are the most prominent challenges faced by the practitioners today and identify that the ICT impact, ethical values and the globalization trend in accounting and financial reporting are some of the most emergent ones. These factors make the work of the practitioners more and more demanding and as it seems difficult to remain competitive in such a dynamic environment, we conclude with the recommendations that the curricula of the financial and accounting higher education should be adapted to include topics such as IAS/IFRS, ICT, Code of Ethics and that the professional accountancy and auditing organizations in Albania should provide ongoing training and qualification sessions on the same topics to the existing practitioners.
\end{abstract}

Keywords: accounting, auditing, accounting software, tax reporting.

JEL codes: $M 40$

\section{Introduction}

During the last twenty years since Albania opened to the free market economy in 1990 a lot of changes have encompassed all the dimensions of its economy. Along with the radical transformation of the overall economic system, the necessity to create new legal and institutional infrastructure capacities was also strongly encouraged. This infrastructure would be critical for the new economic system in achieving success (or experiencing failure). Therefore in the early 90s' a lot of changes were made in the legal framework for regulating the new market regime according the rules of the open market economy and extensive efforts were made on building the necessary infrastructural capacities through deep reforms and innovative measures in many sectors. Accounting, finance and auditing were among the many disciplines that experienced fundamental changes.

The introduction of the independent accounting and auditing professions came naturally after the changes experienced in the political, social and economic life of Albania after the 90's. Developments such as implementing a new open economy after the free market rules, the transformation of the state-owned enterprises into private companies, the establishment of new private entrepreneurships and the need for exercising appropriate and expert supervision and management of the private property required the coming into existence of several new professions, including the independent accountants and auditors. All the changes experienced by the Albanian economy after the 90's would have not been successful without the support of the services offered from qualified experts, among which accountants and auditors played a very important role.

\footnotetext{
${ }^{1}$ Tirana University, Faculty of Economy, Albania, e-mail: rezarta.perri@unitir.edu.al, rezartaperri@gmail.com

2 Tirana University, Faculty of Economy, Albania, e-mail: brikena.leka@unitir.edu.al

${ }^{3}$ Tirana University, Faculty of Economy, Albania, e-mail: rovena.bahiti@unitir.edu.al

${ }^{4}$ Sevasti and Parashqevi Qiriazi University, Faculty of Economy, Albania, e-mail: egishto@gmail.com
} 
During the last twenty years the independent accounting and auditing professions in Albania have gone through a lot of changes and efforts to improve the quality of services offered to the public. The legal framework has been completed with new laws and regulations written in accordance with the requirements presented by the European Union (being an aspirant country to EU Albania has signed agreements to adopt a legal framework fully compliable with that of the EU). The development of such a complete legal structure has consequently presented the opportunity to build an appropriate institutional infrastructure that would have all the necessary tools to regulate and supervise the professions of independent accounting and auditing. Nowadays, after 20 years of full scale reforms Albania possesses adequate (regulatory and supervisory) instruments to guarantee qualitative accounting, auditing and financial services to public and private companies, maybe in the same scale that these services are also offered in other European countries that are in the same development stage as Albania is. However, as the domestic economy needs and the global economy pattern continually changes and Albania is already interconnected in every aspect with the developments occurring in other countries, new needs and challenges are constantly presented to the practitioners of finance, accounting and auditing. As the world is becoming "a small village" the practitioners of these fields even in a small country like Albania have to strive to remain competitive in order to survive in face of the inflow of expertise offered by peer professionals from the surrounding countries of the SEE region or from the Western developed countries.

This study is designed as a theoretical discussion about the most pressing issues that the independent professionals (accountants and auditors) are currently facing in Albania. We aim to present some of the main challenges these professionals are dealing with and also try to give recommendations that may serve as optimal solutions to these problems. The methodology of the paper is based on searching publications, reports and studies of other scholars, governmental agencies and independent institutions to identify which are the most debated themes and the most demanding issues with which the independent accountants and auditors have to deal.

The rest of the paper is organized as follow: in the following section we make a brief review of the recent developments of the accounting/auditing profession in Albania for the last twenty years and describe the status of its current organization. Next, we list some of the most pressing challenges that the accountants/auditors in Albania are facing in the threshold of the new century. Even though we put Albania in the focus of this section, the problems we discuss, we believe are coherent for other South and Eastern European Countries as well as they are going through similar transition periods. In the last section we conclude by summarizing the main findings and by presenting several recommendations that could improve the response of the practitioners toward the discussed challenges.

\section{A brief review on the development and organization of the accounting/auditing profession in Albania.}

After the '90s the new laws on accounting/auditing in Albania were written and approved primarily having the Western legislation in mind and to some extent also the experience of other Eastern European countries, that similar to Albania were also undergoing a phase of transition (Nachescu, et al. 2010). One of the most important earliest steps in the accounting/auditing profession reform was the approval in 1993 of the "Law on Accounting", in which the general obligations, the principles and rules for accounting, preparation and presentation of financial statements were for the first time defined in detail (Shkurti, Leka, 2010). This law established the first Albanian generally accepted accounting principles (GAAP) and also became the foundation on which in the same year, a General Accounting Plan ${ }^{5}$ (GAP) was outlined by the Albanian authorities. The accounting schemes prescribed in the 1993 GAP focused on common financial

${ }^{5}$ General Accounting Plan (GAP) - Ministry of Finance and Economy, 1993. 
transactions carried by the economic enterprises regardless of the specific type of the economic activity they performed (production, trade or services), thus not being quite adequate for application by entities operating in other "special" sectors like financial institution or public utilities companies. Nevertheless, as the GAP aimed to precede and address many general financial and accounting transactions its introduction played a very important guiding role for the practitioners in the dawn of the market economy in Albania.

The GAP has been undeniably an important cornerstone in the Albanian post 90s' accounting regime but the XXI century with its new developments posed new demands and revealed the shortcomings of the GAP itself as well as of the existing "Law on Accounting". Transformations like the sophistication of the domestic financial and economic market; the entrance of important and big foreign companies in the Albanian economy; the determination of the Government to proceed toward EU integration; as well as other factors put an increasing pressure on the accounting/auditing practitioners to offer services of a higher quality. These developments demanded also changes in the organization and structure of these professions. Hence in 2004 Albania approved the new law "On Accounting and Financial Statements" 6 and in 2009 approved a new law "On Legal Auditing, and the Organization of the Profession of Chartered Auditors and Certified Accountants"7. The first law tried to address and overcome the shortcomings of previous accounting procedures and financial reporting practices in Albania while the second aimed to regulate the professions of the certified accountants and chartered auditors prescribing precisely definite rules for their licensing and subsequent supervision in order to guarantee maximum quality. Two important changes presented by these laws were also the foundation of the National Accounting Council (NAC) of Albania which is mandated as the only responsible and authoritative body to compile the National Accounting Standards (NAS) in full compliancy with the international accounting standards IAS/IFRS, and the creation of an independent Public Supervisory Board (PBS) which would be responsible to oversight the activities of the freelance practitioners (accountants/auditors) and to undertake the necessary corrective measures to guarantee fulfillment of laws and Code of Ethics and Professional Conduct.

Obviously, the approval in 2006 of the new NAS may be considered one of the most important changes that have affected the landscape of the accounting/auditing regime in Albania. They have been effective for reporting years beginning in January 2008 and are mandatory for all the Albanian economic entities except those that are required to report under full IAS/IFRS (public entities, financial institutions, etc), or those that deliberately chose to do so. Hence, there have been three years now that the economic entities in Albania are filing their financial statements under the NAS, what is considered by many to be an important progress toward enhancing the financial information quality. However, the opinions in this regard differ substantially as according to other studies (Shkurti, Naqellari, 2010) the implementation of NAS has been in place only for a fairly short time which is not enough to observe qualitative changes and that the level the field practitioners perceive the increase in financial information quality is not as high as that perceived by the regulating authorities. Therefore, in order to guarantee the maximum efficiency of the NAS still a lot of efforts are required on behalf of the regulating authorities (especially the NAC of Albania) and by the practitioners themselves.

Unlike the practice of several other countries where one individual may be licensed to practice both the accountant and the auditor professions, the new legal framework in Albania demands the professionals to choose between being licensed either as auditors or as accountants ${ }^{8}$.

\footnotetext{
${ }^{6}$ Law 9228, date 29.04.2004 "On Accounting and Financial Statements" - available from the www.qpz.gov.al

${ }^{7}$ Law no 10091, date 02.03.2009 - available from the www.qpz.gov.al

${ }^{8}$ Nevertheless, the new law no 10091 allows the certified auditors to perform accounting services (namely preparation of financial statements) to clients with whom that do not have (or have had in the past) auditing services contracts for the same financial statements. Thus, the scope of auditors' work is broader than that of accountants by including accounting and auditing/assurance services, while accountants can provide accounting services only.
} 
The rationale behind this requirement is to provide a clear separation between the accounting and auditing functions by striving to eliminate the risk of overlapping the process of preparing the annual financial statements (performed by the accountants) and the process of auditing these financial statements (carried out by the auditors). This is believed to guarantee qualitative and reliable financial information and on the other hand tries to avoid potential situations where conflicts of interest could be present.

The new laws provide several criteria that individuals aspiring to be licensed as a Certified Accountant should comply with:

a) Having an economic major in fields like finance, accounting, business administration or economics;

b) Having at least three years of experience in accounting, finance and/or financial control, or other related fields;

c) Attending one season of pre-examination qualification courses in accounting and financial reporting. These qualification courses are administered by the accounting associations in Albania;

d) After attending the qualification courses they have to successfully pass two professional proficiency examinations (one covering topics such as accounting, financial reporting and financial statement analysis and the other the civil law, labor act and company act of Albania).

On the other hand, the procedures and criteria to be licensed as a certified auditor are somewhat different. They have to undergo not only the two professional proficiency examinations required for the certified accountants but also to other three (five examinations in total) covering areas such as Code of Ethical Conduct, International Standards of Auditing (ISA), and Fiscal Legislation in Albania. They also have to attend longer seasons of qualification courses spread in a three years time span, during which the candidates for becoming certified auditors have to perform also practical work affiliated with a certified auditor with adequate experience. Candidates who have got the CPA or ACCA certification in another state/country are exempted from three examinations and are required to pass only those covering Albanian legislation topics.

By the time of this study (March 2011) three professional accountancy associations operate in Albania: (i) the oldest is the Institute of Certified Accountants (ICA) founded in 2000 under the previous name "Professional League of Certified Accountants" but known as ICA since 2006; (ii) the Association of the Accountants and Finance Experts of Albania (AAFEA) founded in 1998; (iii) the Association of Certified Accountants, ACA founded in late 2009. The main responsibilities of these professional associations as mandated by law are: 1) to maintain an updated registry of the Certified Accountants that are registered as their members; 2) to provide ongoing trainings and qualifications for their members and for the candidates prior to the professional tests mentioned above (Law no. 10091, 2009). In Albania there are currently about 1200 registered Certified Accountants, but not all of them are licensed with a business license, as the law permits them to not necessarily exercise the license in practice but either to be employed in a company or to work with one-another under the same business license.

Concerning the certified auditors, the law mandates only one professional organization as the responsible authority to organize, regulate and supervise the work of the chartered auditors. The Albanian Institute of Chartered Auditors (IEKA, alb.) operates as an independent association but supervised by the Public Supervisory Board (mentioned above) and assisted in its activities by two important separately functioning organisms, the Certification Authority (responsible to administer the process of certification of the new certified accountants and certified auditors), and the Registration Authority (responsible to implement the registering procedures of certified auditors and auditing companies both Albanian and foreign). Referring to the data from the National Registry of Chartered Auditors (available in www.ieka.org), last updated in November 2010, Albania has around 150 certified auditors and 40 domestic and foreign auditing firms. 


\section{Some challenges for the accounting/auditing professionals in Albania.}

Following the above overview of the current organization of the Albanian accounting/auditing professions we may realize that these sectors have been transformed by deep reforms especially during the last five years. These internal developments along with external demands (that is demands beyond the requirements of the profession itself), have introduced new challenges and pressures for these fields' practitioners. Especially in the context of a changing environment, domestically and abroad, it is quite timely to discuss about the problems that accountants/auditors are facing and which are the new skills they should posses in order to survive in the face of an increasingly tough competition from outside consultants. It is also important to reconsider the role of the accounting specialist in the "information age" so as the accounting may not lose ground toward other "knowledge workers". We have identified four primary challenges that mainly prevail in the discussions about the most emerging issues the Albanian accountants/auditors should be facing at present: (1) the trend of Global Accounting Standards unification, as part of the broader "global accounting" phenomenon, and the costs/benefits associated with this phenomenon for a small country like Albania; (2) the role the accountants could play in the fight against corruption as potential whistleblowers; (3) the way that the information and communication technology (ICT) is affecting the accountants/auditors work and; (4) problems presented by the frequent, unpredictable and inconsistent changes of the reporting requirements (financial and fiscal).

\section{Global Accounting Standards unification trend.}

It is obvious that recently the trend of unifying the accounting standards has encompassed not only the big developed countries but also the small developing economies all around the world. The term "global accounting" is often used to refer to this trend. While a majority of countries have fully or partially endorsed the IAS/IFRS, the biggest unification act is still to come, that of convergence of the IAS/IFRS with the US GAAP (the latter still having a major impact on many big corporations registered in USA or listed in the USA stock markets). Therefore, as more and more countries are complying with the international standards or are preparing domestic standards which conform to the IAS/IFRS, several benefits such as the facilitation of the capital flow and the increased foreign direct investments because of the considerable reduction of the costs of converting from one set of rules to another, are becoming more evident.

Nevertheless, there is a discussion going on, focusing on the idea if the design of global accounting standards may be the best choice for small countries with mainly small businesses like Albania. These debates originate from the evident fact that there exists a trade-off between the cost and benefits of adopting internationally compliable standards. On one hand, adopting the NAS fully compliable with IAS/IFRS, as one of the many requirements for achieving appropriate financial regulation in the framework of fulfilling the conditions of EU integration, has given Albania a lot of political advantages but not many economic advantages given the limited number of big companies in Albania aspiring to attract foreign investments. On the other hand, for the small and medium enterprises, which account for more than $95 \%$ of the Albanian companies, it has been a significant cost to adopt the new NAS because of the need to train the internal staff or to hire outside consultants with higher accounting services fees. Sometimes, the field practitioners (accountants and auditors), more than other experts, have experienced the increased burden to grasp and apply the new knowledge in a short time span.

No study has been conducted yet to measure the costs directly and indirectly related to the implementation of the NAS in Albania, but the overall conclusion is that the applying global accounting standards may result more costly for small countries like Albania that don't have an active capital market that would benefit from better accounting rules and more transparent financial information. However, considering the aspiration of Albania to become an integrative part of the 
EU market we believe that the initial technical difficulties that the practitioners are currently facing and the expensive requirements will eventually pay off in the long-run.

\section{Accountants and auditors as potential whistleblowers.}

Rieger (2007) reports that the SEE countries are generally characterized from a high perceived level of corruption what is often attributed to the lack of appropriate regulation tools and weak law enforcement. This implies high financial risk for foreign and domestic investors and the existence of "shadow economies" of significant dimensions. Albania, being a country within the region, reflects the same features of corruption", lack of transparency and "bribery culture". Obviously, a sound investment environment generally requires high level of financial transparency and adequate procedures in place in order to protect the interests of minority and majority shareholders. In case of the SEE countries, which have high political risks indexes we may add to this list of the requirements also the immunity from the government and political manipulations.

In such a risky environment landscape the accountants and auditors could play a key role in increasing the overall financial transparency, by preventing or detecting corruptive practices through exercising their profession with integrity and abiding to the requirements of the code of ethics. As these professionals are constantly being pressed from their employers to engage in doubtful financial/accounting transactions, to submit fraudulent financial statements, or to participate in any tax evasion schemes, they can be viewed as potential whistleblowers that could choose either to obey their employers' requests or to report these phony practices. Making such a choice usually depends on the level of their professional expertise but primarily on their integrity and other ethical and moral values they exercise in their work. The problems they face require high technical skills as well as strong beliefs to oppose old and deeply rooted corruptive accounting practices, which aim to evade taxes. Therefore the way these practitioners react to the pressures from their employers or clients more than by their professional preparation, depend on their ethical values. These ethical rules generally establish the models of their work and act as an antidote for not letting them compromise with the existing practices but choosing instead to apply correct and transparent procedures.

The resistance of practitioners with professional integrity guarantees high information quality because of compliance with laws and sound financial reporting practices. Thus, the role of accountants as potential whistleblowers is extremely crucial and they have to be "educated" and informed of this potential and of the huge difference they can make in their working environment.

\section{ICT and accounting/auditing professionals in Albania.}

During the last three decades nothing has impacted accounting and auditing more extensively than the growing use of computerized accounting software. Innovative technology concepts like Electronic Fund Transfer, Electronic Data Interchange, Point of Sales, Radio Frequency Identification devices, Enterprise Resource Planning systems, and others, have definitely changed the way that the accounting information is gathered, processed and reported. Nowadays, thanks to the above technologies, the role of the accountants is transformed from simple bookkeepers that only used to capture and process data (this is now done by computers, via POS, RFID, etc.) to participative and important decision-makers. Thus, leaving the routine and repetitive tasks to computers, accountants can focus in analyzing information and playing a crucial role in the decision-making arena of their companies.

Before '90s in Albania there was no use of computers in accounting. All the accounting procedures were manual, taking a lot of time and extra efforts to prepare reports which often were

\footnotetext{
${ }^{9}$ The last Transparency International Association report on the level of perceived corruption index ranked Albania in the $87^{\text {th }}$ place for 2010 with an index coefficient of 3.3. This is 8 places up (decrease in corruption) from the $95^{\text {th }}$ place for the 2009 with a score of 3.2 .
} 
not error-free. But after the '90s with the introduction of the market economy the first computers began to be used in accounting and finance. In 1996 Albania had its first domestic accounting software, the Alpha Accounting package, which was very successful and was soon followed by improved versions of the same software and by other packages which aimed to fill the needs of the enterprises for fast and reliable financial information. Currently in Albania there are a lot of accounting software solutions in the market varying from simple packages for small businesses to modular software, easy ERP and full ERP for big companies. Eminent accounting software firms like SAP, Oracle and WinLine Mesonic have also entered the Albanian market mainly focusing on the big companies, banks and financial institutions. As of today there is hardly no more manual accounting even in the smallest firms because the low-cost accounting packages that are offered in the market.

As expected, learning to use the computerized accounting software (and computers in general) has proved more troublesome for those accountants who were graduated and experienced before the '90s. Hence, it is not unusual in Albania to have certified accountants and even chartered auditors that do not feel familiar enough with neither of the accounting software, and require the help of their assistants when it comes to operate one of these packages. Nevertheless, as everincreasing numbers of workforce are being constantly introduced in the Albanian marketplace ${ }^{10}$, and as the professionals, trying to remain competitive, increase their efforts to learn the accounting packages, this is a phenomenon which is not expected to last for a long time.

Recently, there have been several major changes related to the ICT use and which have affected the work of accountants and auditors in Albania. The latest initiative of the tax authorities in Albania, as part of a broader strategy to decrease the levels of the "shadow economy" is the integration of the accounting packages of the companies with applications like the POS and cash registers. The smart chips of the electronic memories of these registers are connected online with central databases of Regional Tax Authorities transferring in real time information about the cash transactions occurring in each economic entity, thus reducing the possibility of deflating revenues and evading taxes. Another requirement imposed last year on companies subject to the VAT tax in Albania is the obligation to file online (only) all their monthly tax returns. This has decreased extensively the manual work during the preparation of the fiscal reports, reducing errors and saving costs because of limited use of paper-based reports.

\section{Unpredictable, frequent and inconsistent revisions of the reporting requirements.}

As mentioned above, Albania like other countries in the SEE region is considered to have a relatively significant level of political risk. The frequent changes of the financial and tax reporting requirements and the unpredictable revisions of the fiscal policies have contributed considerably in increasing this risk by creating an inconsistent and unstable environment for foreign and domestic investors. They have to constantly follow-up the changes made by the Albanian government and/or the parliaments' decrees in order to carefully and timely implement all the revisions, otherwise they may get penalties. Even though Albania has made efforts towards improving the investing environment in Albania with policies like flat taxation (implemented first in 2006), the so-called "Albania for one Euro" policy to attract foreign investors, and establishing the "one stop shop" centers which deal with registration and licensing procedures of new companies, the expected success is not observed in practice probably due to the confusing reporting environment.

Yet another difficulty arises because of the fact that the Albanian fiscal legislation contains a lot of contradictions and overlapping and sometimes it does not even address at all some very important topics. This leads not only to the increase of the political risk level (improper legislation framework is considered to be a part of the political risk in Albania - Perri, Zani, 2008) which

\footnotetext{
${ }^{10}$ It is estimated that approximately 1000 students are graduated each year in the Albanian universities with any of the economic degrees adding to the workforce as future accountants and auditors (authors' estimation).
} 
brings withdrawal of investors but also to ambiguity for the accounting and auditing practitioners. In addition to that, the current legislation creates frictions between the business and the tax authorities and between the field practitioners and tax authorities, because as unclear and inconsistent as it is, it gives to the tax controllers full powers to interpret the uncertain sections of the law according to their beliefs and opinions (ROSC Report, 2006).

All these frequent changes of the reporting framework and its existing contradictory requirements are not only one of the biggest challenges of the everyday work of accountants and auditors but also a major hidden cost they have to bear in order to provide to their employers and clients updated services up to the "latest revision". This becomes even more important for those freelance professionals that offer accounting services for small companies because of their primary need to file tax reports instead of financial report. As the financial reporting environment in Albania has been quite stabilized and regulated after the implementation of the NAS in 2008, the same cannot be told about the tax reporting framework. It continues to experience frequent and ongoing changes - at least two or three updates/revisions in any of the laws related to market, companies, finance etc, is published each month in the Official Legislation Journal in Albania (authors' observation). Such a fast pace makes it difficult for the accountants and auditors to focus on financial reporting requirements as the tax reporting requires a lot of time and attention, especially if we bring in mind that the transition to the new NAS happened in a single move and allowed three years (from 2006 to 2008) for practitioners to become familiar with them, while on the other hand the changes in the tax reporting happen in an unpredictable manner, all the time and do not allow a long time to know and implement them in practice.

\section{Main findings and conclusions.}

In this article we focus first on a presentation of the current organization of the professions of accounting and auditing in Albania and next we present some of the most emerging challenges they are facing in their work due to internal and external factors. Recently the role played by accounting and auditing practitioners is changing rapidly and as the pace of these changes continues to accelerate it is necessary to pay attention to the requirements posed by the latest developments. When it comes to discuss about the challenges and issues accountants and auditors have to face in a small country like Albania, we have to keep in mind that the pressures they bear are doubled because of the modest past these professions used to have in Albania prior to '90s and the extensive demands on them to become and remain competitive in a market which is now open to foreign expertise and consultancy workforce and developing domestic experts as well.

We identify and thoroughly discuss in our paper issues like unification of the accounting standards, the role of accountants/auditors as potential whistleblowers, the impact of the ICT and the unstable reporting environment, that seem to present the major hindrances for the today's professionals in Albania. The introduction of the new NAS in 2006 and their first implementation in 2008 represent one of the main milestones in the revolution of the accounting and financial reporting after the '90s. It was a revolutionary step which continually requires from accountants and auditors to develop through trainings and qualifications adequate capacities to be able to correctly implement NAS in practice. On the other hand, the increasing use of computerized accounting software and the impact ICT has upon accountants and auditors also requires them to be prepared and appropriately trained to operate these software thus tapping on the potential ICT has brought during the last three decades. Another important role that we assign to accountants and auditors is for them to provide transparent and reliable financial information by abiding to the financial and fiscal reporting requirements and to the ethical values instead of conforming to the requests of their employers or clients to engage in fraudulent schemes.

The important issues presented in the paragraph above require from accountants and auditors on one hand to be adequately equipped with appropriate knowledge to implement NAS (or IAS/IFRS) and to operate the computerized accounting software, and on the other hand to be aware 
of the ethical values and rules which are supposed to encourage them in their role as whistleblowers in their work environment. All these requirements may be met only by proper and full education and training programs. That is why as the main recommendations to overcome the difficulties and to successfully confront the current challenges we put forth the revision and enrichment of the higher education curricula and the ongoing professional trainings that could be organized by the professional accounting and auditing associations to provide their member with updated information and knowledge. Including topics of interest such as IAS/IFRS coverage, tax reporting requirements and adaptation, professional ethics and Code of Ethical Conduct, or accounting information systems in the curricula of the accounting and auditing programs of universities would provide the practitioners-to-be with a full conceptual framework for their future work and behaviors. Thus they would be prepared what to expect when becoming professionals in accounting or auditing. Alternatively, including the same topics in continuous training and qualification programs (that could be administered by domestic professional associations) would bring obvious benefits for the practitioners who have been graduated before ' 90 s or even after ' 90 s but lack the knowledge about these fields.

\section{References}

1. Hoxha E., Bollano J., 2009. Accounting Standards in Albania: Challenges of first time application of AS in Albania, International Conference "Economic Policy and EU Integration", organized by the Durres University, November 2009.

2. Nachescu, et al. , 2010. Report on the development of the audit profession in Balkans after 1990, 2nd Conference of Balkans and Middle Eastern Countries, September 2010.

3. Perri R., Zani B., 2008. Risk of legislation changes as part of political risk - the case of bankruptcy law in Albania, 1st International Conference of the Albanian Center for Risk Studies, November 2008.

4. Rieger R. J., 2007. South East Europe Implementing and Enforcing International Standards for Financial Reporting and Auditing. Discussion paper. Available online at http://www.oecd.org/dataoecd/55/37/32387429.pdf.

5. Shkurti R., Leka B., 2010 . Development of the profession of accounting in Albania in the new century, Working paper, University of Tirana, January 2010.

6. Shkurti R., Naqellari J., 2010. Quality of financial and accounting information in Albania as perceived by the practicing accountants, Journal of Accounting and Finance, no 47, p. 110122 , July.

7. Law 10091, date 02.03.2009 "On Legal Auditing, and the Organization of the Profession of Chartered Auditors and Certified Accountants" - www.qpz.gov.al

8. Law 9228, date 29.04.2004 "On Accounting and Financial Statements" - www.qpz.gov.al

9. Ministry of Finance and Economy of Albania, 1993. General Accounting Plan.

10. National Accounting Standards, available online at www.kkk.gov.al

11. Transparency International. "Report on corruption perceptions index 2009" and "Report on corruption perceptions index 2010". Available online at http://www.transparency.org/policy_research/surveys_indices/cpi.

12. World Bank (WB), 2006. Report on the Observance of Standards and Codes on Accounting and Auditing (A\&A ROSC) in Albania. 